Bol. Acad. peru. leng. 61.2016 (161-181)

\title{
El cometa Halley, Ricardo Palma y un artículo embozado
}

\author{
Halley's Comet, Ricardo Palma \\ and a hidden article \\ Oswaldo Holguín Callo \\ Academia Peruana de la Lengua \\ Pontificia Universidad Católica del Perú
}

\section{Resumen:}

Ricardo Palma publicó en la revista limeña Variedades, en 1910, un artículo jocoso sobre el próximo paso del cometa Halley, desconocido hasta el día de hoy por haber salido bajo el seudónimo Savonarola. La ocurrencia cósmica le permitió recordar que el anterior paso del citado cometa se produjo en 1835, cuando él solo tenía dos años, y a sus hijos Clemente y Ricardo les dio la oportunidad de escribir artículos fantásticos que publicó la prensa limeña.

\section{Abstract:}

Ricardo Palma published in a Lima magazine, Variedades, in 1910, a humorous article about the next approach of the Halley's Comet. This article was unknown until today since it was done by the pen name of Savonarola. The cosmic witticism allowed him to remember the previous approach of the comet 
occurred in 1835, when he was only two years old, and it gave to his children Clemente and Ricardo the opportunity to write each with his own fantastic articles that the Lima press published.

Palabras clave: Ricardo Palma, cometa Halley, literatura peruana humorística, revista Variedades.

Keywords: Ricardo Palma, Halley's comet, humorous Peruvian literature, magazine Variedades.

Recibido: 30/11/2016

Aceptado: 15/12/2016

\section{Savonarola, ergo Palma}

En la edición 103 del influyente semanario limeño Variedades, dada a luz el 19 de febrero de 1910, los lectores encontraron un artículo a toda página datado tres días antes bajo el título «Ojo con el 18 de mayo de 1910», suscrito por alguien embozado con el seudónimo Savonarola, nombre del fraile dominico que a fines del siglo XV predicó fervientemente en contra de la mala vida y los vicios de la sociedad florentina, a la cual aseguró castigos horrendos si no se reformaba. Quien estaba detrás de tan sugerente seudónimo no era otro que el viejo director de la Biblioteca Nacional, Ricardo Palma, que por esos días había cumplido setenta y siete años $\mathrm{y}$, a pesar de sus achaques, aún emprendía y culminaba proyectos literarios y editoriales de relativa monta ${ }^{1}$.

1 La prueba de la autoría palmina del artículo la hallamos en una carta de don Ricardo a su hijo Ricardo Palma Román, Lima 22 de febrero de 1910, donde le dice: 
Hasta el presente, ningún investigador histórico o literario, o palmista viejo o novel, ha dado cuenta de este artículo, como tampoco se sabía que alguna vez Palma hubiera empleado dicho seudónimo.

Ponerse la máscara de Savonarola tuvo el claro propósito de esconder la identidad del autor del artículo: el viejo tradicionista que dirigía con aplauso la Biblioteca Nacional y desde hacía muchos años se hallaba apartado de la política. Precisamente, las alusiones políticas presentes en el texto, aunque muy repartidas, no iban bien con la imagen neutral o imparcial que Palma se había construido y deseaba conservar. Otra razón de peso que recomendó el empleo del seudónimo pudo ser el espíritu risueño y jocoserio presente de principio a fin en el artículo, el cual se alejaba de la solemnidad propia del escritor e intelectual venerable en que se había convertido su autor. Sin embargo, creo no equivocarme al pensar que más de un lector de Variedades identificó a Palma detrás del misterioso seudónimo en gracia al estilo, al lenguaje y a otros aspectos del texto.

El artículo palmino respondía a los sensacionalistas anuncios del afamado astrónomo francés Camille Flammarion, quien, ante el esperado paso del cometa Halley $^{2}$, había ofrecido unas proyecciones francamente aterradoras que los periódicos del mundo se habían

«Te mando certificado un paquetito con el número Almanaque de Caras y Caretas y el número último de Variedades, con mi artículo sobre lo que nos espera para dentro de noventa días - el 18 de mayo» (Ricardo Palma. Cartas indiscretas, pág. 92). El último número de Variedades referido solo puede ser el 103.

2 Llamado así por el astrónomo inglés Edmond Halley; véase Heather Couper y Nigel Henbest. The history of astronomy, págs. 170-178. 
encargado de difundir para estupor de todos y, cómo no, sustancial incremento de sus ventas. Flammarion sostenía que la Tierra atravesaría la cola del cometa, la cual, al estar compuesta de gas cianógeno, acabaría con la vida humana y todas las demás ${ }^{3}$.

\section{Humorismo y política}

«Ojo con el 18 de mayo de 1910» es un artículo humorístico, no ajeno al humor negro, con alusiones políticas de actualidad. Palma se presenta embargado por el temor ante la «mataperrada magna» que se avecina, asegurando que mayo es el mes de las grandes mataperradas, lo que demuestra al recordar la aventura revolucionaria de Augusto Durand y la más reciente de los pierolistas al mando de Isaías de Piérola en contra del presidente Leguía. Sin embargo, asegura que «todo es hojarasca de buñuelo comparado con lo gordo que nos espera» el próximo 18 de mayo, y que se ha decidido a dar la campanada de alarma para que «la mataperrada magna no nos coja de sorpresa sino confesados, oleados y sacramentados». En ese sentido, pronostica que los políticos civilistas Ántero Aspíllaga, presidente de la Cámara de Senadores, Ernesto Zapata y Rafael Villanueva, ministros de Estado, cada quien por su propia circunstancia, verán cambios radicales a raíz del 18 de mayo: Aspíllaga «no saldrá [...] proponiendo a los civilistas de su camada un votito de confianza ni en el Padre Eterno. Bien escamado anda con el de la semana

3 «In 1910, for the appearance of Halley's Comet, he believed the gas from the comet's tail would impregnate [the Earth's] atmosphere and possibly snuff out all life on the planet» (https: / / en.wikipedia.org/wiki/Camille_Flammarion, revisión 30 de octubre, 2016). 
pasada», Zapata "puede ir muy tranquilo a contestar las interpelaciones que le formulen sobre las toneladas de fierro, cobre y plomo que quiere obsequiar al océano. ¡Vaya una tutuma!» y Villanueva «y sus colegas serían eternamente inamovibles, como enclavados con tuerca $\mathrm{y}$ tornillo en las poltronas ministeriales, si no estuviera ad portam el 18 de mayo».

La estrategia de Palma es callar el motivo de sus temores y sobresaltos en toda la primera parte del artículo, ciertamente con el fin de suscitar en el lector una fuerte curiosidad que despeja en la segunda parte, valido de la información periodística que a la sazón circulaba sobre el tema. Es solo entonces que el lector descubre la causa de tantas alarmas y malos augurios: el coletazo -Palma dice colazo- del cometa Halley previsto por Flammarion. El desarrollo de esa información no lo priva de rematarla con nuevas muestras de su espíritu burlón, pues si no se produce el coletazo, cree Flammarion que se podría dar una lluvia de estrellas errantes o, si

Dios nos libra de que una nos rompa la cabeza o nos calcomanice [sic] tendremos, por lo menos, una prodigiosa aurora boreal. Por si acaso, y para que lo último suceda, voy a ponerle una lámpara a cada una de las once mil vírgenes. No es flojo el gastito que voy a hacer.

El párrafo final descubre el poco crédito que los cálculos del astrónomo francés le merecen: el 18 de mayo «corremos el riesgo de que [...] seamos víctimas de una gran mataperrada, no por obra de politiqueros de plazuela sino de astrónomos fantaseadores». 
¿En qué fundaba Palma la completa seguridad que le hacía despreciar por fantaseadores los cálculos de Flammarion? Aunque no lo dice, se apoyaba sin duda en la opinión de otros científicos y en su propia experiencia de hombre fogueado en actitudes escépticas frente a los pronósticos más alarmistas. En realidad, no era la primera vez en su vida que había escucha-do pronósticos apocalípticos. En el siglo XIX, el austriaco Rudolf Falb difundió una teoría sobre terremotos y erupciones volcánicas que causó estupor durante mucho tiempo. Palma recordaba semejantes predicciones ${ }^{4}$.

En las semanas siguientes, Palma se ocupó del cometa una y otra vez en la correspondencia que regularmente mantenía con su hijo Ricardo Palma Román, médico de la hacienda Cayaltí: "Venga en buena hora el 18 de mayo con el colazo del cometa para dejarnos en paz al Gobierno y a sus acreedores» (Palma 1969: 93).

\section{Antecedentes y circunstancia}

Los cometas no eran nuevos en el universo literario palmino. Algunas tradiciones contienen referencias funestas originadas en ellos. Así, en «Un virrey hereje y un campanero bellaco. Crónica de la época del decimoséptimo virrey del Perú» leemos: «Para acrecentar el terror de los espíritus, apareció en 1660 el famoso cometa observado por el sabio limeño don Francisco Luis Lozano, que fue el primer cosmógrafo mayor

4 «[Fulano] era el Falb de su siglo, gran pronosticador de temblores y muy diestro en agorerías» (Palma. «Las brujas de Ica», en Tradiciones peruanas completas, pág. 266). 
que tuvo el Perú» (Palma 1964: 403); y en «La Apología del pichón palomino» hace memoria don Ricardo «[...] del principio popular de que los cometas y fenómenos auguran pestes, guerras y demás calamidades públicas...» (Palma 1964: 838). Incluso son parte de unos versos autobiográficos:

\author{
Y eso que dije yo tan verdad era \\ como que hay, en la esfera \\ celeste, estrellas y astros infinitos \\ y cometas crinitos $^{5}$. (Palma 1964: 1459)
}

En realidad, como hombre leído e informado, Palma sabía del extraordinario papel que los cometas habían tenido en la historia universal, que los pueblos antiguos a menudo los habían visto con temor y como aviso de mal agüero. No libre de supersticiones, Palma mostró si no preocupación por lo menos cierto respeto a dichos cuerpos celestes.

Sin embargo, en «Ojo con el 18 de mayo de 1910», una composición de circunstancia, casi una improvisación, Palma, lejos de toda seriedad historiográfica, se revela burlón y divertido. El viejo bibliotecario aprovecha la notoriedad del tema, que a muchos

5 «Sinfonía a toda orquesta». Otras referencias: «Se observó el llamado cometa de Newton» («Un virrey y un arzobispo. [Crónica de la época del trigésimo virrey del Perú]», Palma. Tradiciones peruanas completas, I, pág. 566); en octubre de 1807 se vio en Lima un cometa, y en noviembre de 1811 otro que durante seis meses permaneció visible sin necesidad de telescopio («El virrey de la adivinanza. [Crónica de la época del trigésimo octavo virrey del Perú]», Palma. Tradiciones peruanas completas, III, pág. 852), «Apuesto, lector limeño, a que entre los tuyos has conocido algún viejo de esos que alcanzaron el año del cometa (1807), que fue cuando por primera vez se vio en Lima perros con hidrofobia, y a que lo oíste hablar con delicia de la Perla sin compañera» («El mejor amigo..., un perro». Palma. Tradiciones peruanas completas, I, pág. 858). 
tenía preocupados, para suscitar hilaridad en los lectores y extenderse en alusiones personales que nos lo muestran atento a las noticias y muy al tanto del acaecer citadino, así el político como el social y cultural. Las cartas que por ese tiempo y con regularidad religiosa enviaba semanalmente a su homónimo hijo, prueban largamente su disposición a las novedades de toda laya. Sus hijos, ampliamente relacionados, y los diarios capitalinos, eran sus principales fuentes de información.

Por otro lado, el artículo es una muestra del remozado buen humor de Palma anciano. Escéptico y burlón, la alarmante noticia del cometa que sería la causa del fin de la Tierra vino a proporcionarle un tema harto aprovechable para ejercitar su adiestrada vis cómica. Palma ya no estaba en condiciones de escribir tradiciones que le exigieran una detenida investigación y pulimento. Hacia 1910 debía cuidar el poco «fósforo cerebral» que le quedaba, pues a la evidente decadencia física que sufría se sumaban enfermedades y consejos-órdenes de sus médicos. En tales circunstancias, escribir páginas ligeras pero entretenidas era una alada forma de seguir produciendo literatura, aunque no ciertamente de la mejor calidad.

\section{Los artículos comentarios de Clemente Palma y Ricardo Palma Román}

La «visita» del recurrente cometa dio lugar a preocupación, temores y angustias en muchos lugares del mundo. También hubo quienes especularon mediante la invención y comercio de todo género de artificios para burlar 
sus mortíferos efectos ${ }^{6}$, o se valieron de la imprenta para publicar estudios seudocientíficos y medrar a costa de la ingenuidad de un sector de la sociedad, o hallaron inspiración para soltar la péñola y facturar páginas literarias de varia calidad o para trazar todo género de dibujos y pinturas no ajenas a la caricatura o a la fantasía. Los hijos de Palma, Ricardo y Clemente, y el poeta José Santos Chocano fueron algunos de aquellos. En lo que toca al arte gráfico, uno de los varios dibujos que la prensa limeña reprodujo fue la caricatura política «El cometa de mayo» del artista Francisco González Gamarra, que apareció en la habitual página de «Chirigotas» de la revista Variedades ${ }^{7}$.

Ricardo Palma Román escribió y publicó un artículo sobre el comentado tema. Lo hizo con una mezcla de conocimientos científicos, que los tenía, y mucho humor. Su padre le acusó recibo: «Está bueno el articulito sobre el cometa. Va Clemente a utilizarlo en Variedades» (Palma 1969: 98); y cuando salió a la luz le dijo: «Muy bonito tu artículo sobre el cometa que salió en el número de Variedades, que hoy te remito con sello de la Biblioteca» (Palma 1969: 99) ${ }^{8}$. Suscrito con el seudónimo Dr. Piphan, se titula «Contra cometitas. Invento

6 «En la vuelta del Halley a principios del siglo XX, la cercanía de su paso creó un miedo que impulsó la creación de un importante mercado para "máscaras anti-cometa" y otros artefactos supuestamente diseñados para protegerse de unas posibles emanaciones tóxicas. Hubo gente que se suicidó en Europa central y oriental, por la psicosis creada por los periódicos de que en el momento en que la Tierra pasase por dentro de la cola del cometa las personas de la Tierra quedarían envenenados [sic]» (https: / / es.wikipedia.org/wiki/Influencia_cultural_de_los_cometas, revisión 4 de octubre, 2016).

7 Ed. del 2 de abril de 1910, № 109. Aparecen en ella el presidente Leguía y uno de sus ministros sosteniendo un intencionado diálogo junto a un telescopio.

8 Cartas del 22 y 30 de marzo de 1910, respectivamente. 
notable y de actualidad» y salió acompañado de tres dibujos caricaturescos realizados por el mismo autor, quien simuló un amplio conocimiento del tema para consignar afirmaciones seudocientíficas con un claro objetivo jocoso y divertido 9 . La mención de personajes versados en materias exactas, como los doctores Joaquín Capelo y Federico Villarreal, y los inventores locales Rivero y Carlos Tenaud, buscó darle un aire de seriedad a lo que no pasaba de ser una humorada salpicada de enrevesados conceptos científicos. Palma Román, que se confiesa «versado en achaques de astronomía», ofrece para la salvación del mundo un invento estrafalario - «un aparato morrocotudo, con el que salvaré a mis paisanos y a la humanidad toda, si hay tiempo para tanto»- que promete instalar a quien lo solicite, menos al vocal Rafael Villanueva, pues, «por mi parte, que se lo lleve el cometa a ver las estrellas» ${ }^{10}$. Villanueva, como ministro de Gobierno, había reprimido severamente a los pierolistas después de su fracasada intentona golpista del 29 de mayo de 1909. Es claro que el joven médico de Cayaltí, al igual que su padre, simpatizaba con los partidarios del caudillo demócrata.

Clemente Palma, hijo mayor de don Ricardo, se desempeñaba como director de la difundida revista Variedades. Era un influyente periodista de opinión pero también un respetado crítico literario y un raro escritor de relatos fantásticos. Escondido detrás del seudónimo Klingsor, el 7 de abril publicó la primera parte de su

9 Véase la bibliografía. En nota al pie, Palma Román asegura ser el autor de los dibujos, etc.

10 Ibíd. 
cuento «El día trágico» en la revista Ilustración Peruana que dirigía Pedro Paulet ${ }^{11}$. Anacrónicamente, «El día trágico» refiere la zozobra creada en Lima por los cables llegados de Europa desde el 26 de abril de 1910 anunciando el inminente arribo del cometa Halley y el paso de la Tierra a través de su mortífera cauda, así como la supervivencia de una pareja de norteamericanos gracias a un refugio subterráneo hábilmente construido, todo lo cual, sin embargo, resulta ser solo un mal sueño ocasionado por el desequilibrio nervioso y la fatiga «en el espíritu de un imaginativo» (Clemente Palma 2006: 372). El realismo de las imágenes, la mezcla de ficción y verdad y otros elementos literarios hacen del cuento una pieza que se distingue por la "veracidad» que trasunta, digno producto de quien practicaba una narrativa convincente aunque extraña y esotérica. La última entrega del cuento salió en la edición del 5 de mayo, varios días antes del temido 18, de suerte que Clemente Palma pudo contribuir con su rotunda afirmación final a la serenidad que el vecindario limeño y peruano requería: «El cometa Halley será tan inofensivo como todos los demás cometas...» (Clemente Palma 2006: 372) ${ }^{12}$.

Las producciones que el cometa Halley inspiró a los Palma, padre e hijos, nos dicen de su disposición a valerse de hechos de extendida atención -mundial en este caso- para sus creaciones literarias, pero no menos de su afición a lo extraño y oscuro, inusual

11 Véase la bibliografía.

12 Un análisis de «El día trágico», en Nancy M. Kason, Breaking Traditions. The fiction of Clemente Palma, págs. 49-53. 
y sorprendente, aunque con diferente actitud. Don Ricardo echó a andar su propensión a lo jocoso y a la sátira política, su hijo médico reveló algún humorismo y que de raza le viene al galgo, y Clemente, experimentado en las lides periodísticas no menos que en las literarias, compuso uno de sus novedosos cuentos fantásticos.

El poeta Chocano encontró motivo inspirador en el paso del cometa para escribir «El cometa Halley. "Oda celeste"», un fabuloso coloquio cósmico, en prosa, entre las doce constelaciones, la Tierra, etc. ${ }^{13}$.

\section{El 18 de mayo de 1910 en Lima}

Los funestos pronósticos de Flammarion y otros astrónomos afrontaron los fuertes cuestionamientos de colegas cuyos cálculos echaban por tierra sus predicciones. Se produjo así una situación favorable a la duda antes que a la seguridad que hacía falta para dejar atrás el natural miedo de muchos y la manifiesta intranquilidad de algunos. En Lima, el matemático y científico Federico Villarreal, que ya se había ocupado de los cometas, publicó algunos artículos explicativos y de divulgación en la prensa más influyente ${ }^{14}$. Al promediar marzo sosegó a los preocupados limeños asegurando lo siguiente: «Al atravesar la cola no nos sucederá nada, porque como ya hemos dicho, antes hemos atravesado en 1819 y 1861 otras colas de otros cometas; pueden caer estrellas fugaces o iluminación de una falsa aurora boreal, o bien manifestaciones eléctricas...» (Villareal 1910: 139); y en las siguientes semanas volvió

13 Véase la bibliografía.

14 Luis K. Watanabe. Federico Villarreal: matemático e ingeniero, págs. 245 y 247-248. 
a escribir sobre el tema, siempre animado de un espíritu tranquilizador, y el mismo día 18 de mayo reiteró que no habría un choque del cometa con la Tierra ni cambios en la atmósfera al atravesar su cola y que el fenómeno «sería semejante al paso de un tren a través de la neblina» (citado en Watanabe 2004: 248).

Cercana al fin la temida fecha, el cometa volvió a figurar en la correspondencia de Palma, quien tenía muy presente el funesto pronóstico: 18 de mayo a las 9 de la noche, colazo del cometa Halley (Palma 1969: 117). La víspera del suceso que podría acabar con la humanidad, Palma le dijo a su hijo Ricardo:

No me inspira curiosidad el cometa de Halley. Yo lo conocí, según me contaba mi madre, cuando su aparición en 1835. Quizá el cometa se acuerde de haberme visto las veces en que en sus brazos me sacaba mi madre a la baranda de casa, de siete a ocho de la noche. Si mañana, antes de las nueve de la noche, no nos da el gran zurriagazo, tendré el gusto de volver a ver al antiguo camarada, cuando a fines de mes quiera dejarse ver de seis a ocho de la noche. Por lo demás acabo de escribir en el prólogo de un librejo que, a fines de año, publicará mi editor de Barcelona:

Ya tiene edad para morir mañana quien dos veces ha visto la silueta del cometa de Halley, un cometa que no es anca de rana. (Palma 1964: 119) ${ }^{15}$

15 En efecto, en «A guisa de proemio» (Palma. Poesías completas, pág. 6) insertó la misma cuarteta con una mínima transposición y esta nota al pie de página: «En 1835 y en 1910. Como el cometa tarda setenta y cinco años para volver a visitarnos, no será este servidor de ustedes quien lo espere hasta 1985. Me tiene sin zozobra la caída de su merced». Otro escritor que también vivió los dos pasos del cometa, en 1835 y 1910, años de su nacimiento y muerte, fue el norteamericano Mark Twain. 
Y al fin llegó el 18 y pasó como cualquier otro día limeño de otoño, algo frío, muy húmedo y nublado. Al día siguiente, el diario El Comercio dio cuenta de la angustia que al menos una parte de la población había sentido la noche anterior:

A las 9 de la noche de ayer, en nuestra ciudad, y a la hora relativa en todo el mundo, los dos mil millones de habitantes que pueblan el planeta se han sentido preocupados con el astro errante que les amenazaba con la muerte.

Crédulos y atribulados los unos, ocultando su intranquilidad bajo una máscara de fingido desdén los demás, todos han elevado sus miradas, en una interrogación mezcla de inquietud y de espanto, de duda y de ironía.

El progreso de las humanas ciencias, el grado de cultura a que el mundo ha llegado, le han permitido participar, por igual, en esta expectativa.

[...]

El cielo se presentó nublado anoche, el público que recorría las calles y poblaba las azoteas no tuvo ocasión de ver el cometa ni su cola, por más que suponemos en honor del representante de Halley que esta fuera luminosa y tuviera [sic] adornada de otros atributos celestes.

Sin embargo, ha reinado una calma absoluta; la gente alegre reía del cometa y sin respeto al señor Halley. No hubo actos de intranquilidad, de los que nos relata el cable que han hecho reproducir en algunos lugares de España escenas que recuerdan las que caracterizaron ciertos tiempos de la Edad Media.

La policía tuvo poco que hacer; la gente andaba preocupada con el cometa y en previsión de lo que ocurrir pudiera, guardaba un prudente recato ${ }^{16}$.

16 http:/ / elcomercio.pe/eldominical/articulos-historicos/paso-cometa-halley-causopanico-1910-noticia-1708273, revisión 30 de octubre, 2016. 
En realidad, el zahorí cronista advirtió que muchos habían sentido verdadero miedo:

Pero quien haya leído con espíritu atento, todas las disquisiciones que alrededor del cometa de Halley se han hecho, ha podido ver con claridad que el peligro existía para algunos de ellos, y que si no ha llegado a convertirse en triste realidad y a nosotros en míseros despojos, se ha debido a otras causas que explicarán estudios posteriores... ${ }^{17}$

En efecto, el miedo había provocado angustia, suicidios, disturbios y otras desgracias en muchos lugares del mundo.

El cometa no se hizo plenamente visible en el cielo limeño sino varios días después de la azarosa fecha. Palma lo vio el 25 de mayo, «por primera vez, a las 7 de la noche» (Palma 1969: 121), y el 30 «con más claridad [vi] la cauda del cometa» (Palma 1969: 122) ${ }^{18}$. Para entonces, el miedo y la preocupación habían cesado por completo. Don Ricardo había sido uno de los primeros que rieron e hicieron reír a costa del suceso cósmico que a muchos, él y los suyos incluidos, no dejó de suscitar al menos un sí es, no es de incertidumbre.

Ibíd.

18 Cartas del 28 y 31 de mayo de 1910, respectivamente. 


\section{ANEJO}

\section{Ojo Con el 18 de Mayo de 1910}

Estoy que no me llega la camisa al cuerpo $^{19}$ : ya no es miedo sino terror mayúsculo el que se ha apoderado de mí.

El mes de mayo es el mes de las grandes mataperradas. En un mayo, y no remoto, Durand con sus liberales nos pusieron los pelos de punta ${ }^{20}$. En el recién pasado mayo, Isaías de Piérola con sus demócratas, nos hicieron dar diente con diente ${ }^{21}$.

Pero todo es hojarasca de buñuelo comparado con lo gordo que nos espera para el, ya próximo, 18 de mayo de 1910. No fijo la hora, porque a pesar de mis muchas y prolijas investigaciones no he alcanzado a saberla. ¿Será la cosa en la mañana, en la tarde o en la noche? Repito que no lo sé ni lo sospecho.

Por altruismo purito, por amor al prójimo, me he resuelto a dar la campanada de alarma. Que la mataperrada magna no nos coja de sorpresa sino confesados, oleados y sacramentados. Ya estoy haciéndole

19 «No llegarle a alguien la camisa al cuerpo... Estar lleno de zozobra y temor por algún riesgo o amenaza» (Real Academia Española, Diccionario de la lengua española. 23. ${ }^{a}$ ed., http: / / dle.rae.es/ ?w=diccionario). Nota de $\mathrm{OHC}$, como todas las siguientes.

20 Augusto Durand, jefe del Partido Liberal, encabezó un fracasada rebelión el 1 de mayo de 1908 para derrocar al presidente José Pardo y Barreda.

21 El 29 de mayo de 1909 el presidente Leguía enfrentó una audaz intentona de golpe de Estado ejecutada por un grupo de pierolistas al mando de Isaías de Piérola. 
purisimitas $^{22}$ al padre Pérez $^{23}$, de los descalzos, para que se avenga a confesar y a absolver a este herejote ${ }^{24}$. Que la tremenda me pille con el práctico a bordo ${ }^{25}$. Esta vez la cosa no es de bufonada, sino a la de veras -el 18 de mayo, ténganlo presente. Lo que aseguro es que, en la futura mataperrada, no saldrá don Ántero Aspíllaga ${ }^{26}$ proponiendo a los civilistas de su camada un votito de confianza ni en el Padre Eterno. Bien escamado anda con el de la semana pasada.

El ministro Zapata ${ }^{27}$ puede ir muy tranquilo a contestar las interpelaciones que le formulen sobre las toneladas de fierro, cobre y plomo que quiere obsequiar al océano. ¡Vaya una tutuma ${ }^{28}$ ! El 18 de mayo se encargará de declarar nulo todo lo fecho y actuado contra él.

22 Hacer purisimitas es expresión que solo he hallado referida por Juan Álvarez Vita como limeñismo en desuso (Diccionario de peruanismos. El habla castellana del Perú, pág. 370), pero el significado -«Hacer prodigios de demostraciones y expresiones»- no parece reflejar el sentido que le da Palma, quien no dejó de emplearla en otras ocasiones («La gatita de Mari-Ramos que halaga con la cola y araña con las manos», Palma 1964: 726, y Poesías completas, pág. 305). Clorinda Matto de Turner también la usó con el sentido de solicitud o petición (Aves sin nido, pág. 84). Parece haber sido propia del habla coloquial limeña.

23 Esteban Pérez, franciscano español, notable orador sagrado que realizó misiones populares en diversos lugares del Perú.

24 La idea está repetida en carta a su hijo Ricardo de la misma fecha, 16 de febrero de 1910: «El astrónomo Flammarion escribe desde París que en abril hará su aparición el cometa de Halley, y que el 18 de mayo le dará un colazo a nuestro planeta. Voy a pedirle al padre Pérez que vuelva a Cayaltí, para que la cosa te pille confesado y absuelto» (Palma 1969: 90).

25 Es decir, del técnico que dirige el rumbo de las embarcaciones en un puerto (DRAE).

26 Político civilista, presidente de la Cámara de Senadores.

27 Ernesto Zapata, ministro de Guerra y Marina.

28 «Familiarmente llamamos tutuma a la cabeza» (Ricardo Palma. Dos mil setecientas voces que hacen falta en el Diccionario. Papeletas lexicográficas, pág. 273). Sin embargo, «Vaya una tutuma!» da a entender ser duro de tutuma, o sea torpe (Álvarez Vita 2009: 435). 
Sépase que el doctor Villanueva ${ }^{29}$ y sus colegas serían eternamente inamovibles, como enclavados con tuerca y tornillo en las poltronas ministeriales, si no estuviera ad portam ${ }^{30}$ el 18 de mayo, del que solo nos separan noventa días. Ese 18 de mayo va a ser como un recio chaparrón de agua en la pampa y en el que nadie libra de mojarse, como no hubo pantalones que pasaran en Carnaval bajo los balcones del Centro Universitario, sin baldazo lanzado por manos no de niñas sino de varoncitos. ¡Y qué varoncitos! Los del porvenir ${ }^{31}$.

Como no me han encargado el secreto, voy a hacer público lo que nos espera para el 18 de mayo. El fin del mundo, nada menos, un colazo ${ }^{32}$ del cometa Halley que hará su aparición en abril.

Según Flammarion ${ }^{33}$, que es el sabio astrónomo que en la prensa de París da la alarmadora noticia, la cola del cometa mide más de cuarenta millones de kilómetros, y como el 18 de mayo estará a veintiséis millones de distancia de nuestro planeta, el baño fosfórico es inminente, y no nos dará tiempo ni para decir Dios me perdone. Agrega Flammarion que ya dos veces, en 1819 y en 1861, la tierra ha estado en peligro de que

29 Rafael Villanueva, político civilista, ministro de Gobierno y presidente del Consejo de Ministros.

30 A la puerta.

31 En carta a su hijo Ricardo Palma Román, médico en la hacienda Cayaltí, suscrita el mismo día del artículo, anotó: «Aquí los días de Carnaval pasaron sin gran animación. Solo los jóvenes del Centro Universitario, cuyo presidente es tu colega [Carlos Enrique] Paz Soldán, se singularizaron como maricones, mojando a los hombres» (Palma 1969: 88, resalte original).

32 Colazo, americanismo por coletazo. Actualmente, su empleo en el Perú es raro.

33 Camille Flammarion, famoso astrónomo francés conocido por sus obras de popularización de la astronomía. 
la azotase un colazo; pero que en ambas todo no pasó de una lluvia de estrellas errantes. Quizá lo último lo ha escrito para tranquilizarnos un poquito, con la esperanza de que en esta vez suceda lo mismo. Yo no las tengo todas conmigo, por aquello de que a la tercera vez va la vencida. También cree Flammarion que si no hay lluvia de estrellas y Dios nos libra de que una nos rompa la cabeza o nos calcomanice ${ }^{34}$ tendremos, por lo menos, una prodigiosa aurora boreal. Por si acaso, y para que lo último suceda, voy a ponerle una lámpara a cada una de las once mil vírgenes. No es flojo gastito el que voy a hacer.

Sea de esto lo que fuere, siento regocijada mi conciencia de hombre altruista, con haber avisado a mis paisanos y amigos que corremos el riesgo de que el 18 de mayo de 1910 seamos víctimas de una gran mataperrada, no por obra de politiqueros de plazuela sino de astrónomos fantaseadores.

\section{Savonarola}

16 de febrero.

En Variedades. №103. Lima, 19 de febrero de 1910, pág. 224.

34 Calcomanice, galicismo de significado impreciso. 


\section{Bibliografía}

ÁlVAREZ VITA, Juan. Diccionario de peruanismos. El habla castellana del Perú. Lima, Universidad Alas Peruanas, 2009.

CHOCANO, José Santos. «El cometa Halley. "Oda celeste"», en Ilustración Peruana. № 38. Lima, 22 junio de 1910, págs. 297-298.

COUPER, Heather y Nigel HENBEST. The history of astronomy. Nueva York, Firefly Books, 2007.

KASON, Nancy M. Breaking Traditions. The fiction of Clemente Palma. Lewisburg, PA, Bucknell University Press, 1988. https:// books.google.com.pe / books?id=nZ14Kc7_7jQC\&printsec=frontcover\&dq=breaking + traditions \&hl $=$ es-419\&sa $=$ X\&redir_esc $=\mathrm{y} \# \mathrm{v}=$ onepage $\& \mathrm{q}=$ breaking $\% 20$ tradition $\& \& \mathrm{f}=$ false (revisión 23 de enero, 2017).

MATTO DE TURNER, Clorinda. Aves sin nido. Caracas, Biblioteca Ayacucho, 1994.

PALMA, Clemente (seud. Klingsor). «El día trágico», en Ilustración Peruana. № 31. Lima, 7 de abril de 1910, págs. 149151; No 32.21 de abril de 1910, págs. 180-182; y No 33.5 de mayo de 1910, págs. 196-198.

. «El día trágico. (Crónica de los días del cometa)», en Cuentos malévolos. 2. ${ }^{a}$ ed. París, Lib. de Paul Ollendorff, 1913.

. Narrativa completa. I. Edición, prólogo y cronología de Ricardo Sumalavia. Lima, Pontificia Universidad Católica del Perú, 2006, págs. 344-372.

PALMA, Ricardo. Dos mil setecientas voces que hacen falta en el Diccionario. Papeletas lexicográficas. Lima, Imp. La Industria, 1903. 
- (seud. Savonarola). «Ojo con el 18 de mayo de 1910», en Variedades. No 103. Lima, 19 de febrero de 1910, pág. 224. Data: 16 de febrero.

1911.

. Poesías completas. Barcelona, Casa Editorial Maucci,

. Tradiciones peruanas completas. 5. ${ }^{\text {a }}$ ed. Madrid, Aguilar, 1964.

. Cartas indiscretas. Comentadas por César Miró. Lima, Francisco Moncloa Editores, 1969.

PALMA ROMÁN, Ricardo (seud. Dr. Piphan). «Contra cometitas. Invento notable y de actualidad», en Variedades. No 108. Lima, 26 de marzo de 1910, págs. 389-390, inc. 3 ils.

REAL ACADEMIA ESPAÑOLA. Diccionario de la lengua española (DRAE). Madrid, 2014, 23. ${ }^{a}$ ed. en línea http:// dle.rae. es $/$ ? w $=$ diccionario

VILLARREAL, Federico. «El cometa de Halley», en Ilustración Peruana. № 28. Lima, 17 de febrero de 1910, págs. 87-90, ils.; No 29. Lima, 3 de marzo de 1910, págs. 104-107; y № 30. Lima, 17 de marzo de 1910, págs. 138-139.

WATANABE, Luis K. Federico Villarreal: matemático e ingeniero. Lima, Petróleos del Perú, 2004. 